there, according to the plan sometimes adopted in cases of ovariotomy. As regards the operation itself, which has not hitherto been adopted in this country, it has now been performed on fifteen occasions by Billroth, Wölfler, and others with considerable success, five recoveries having taken place, and one patient was recently described as being alive and in good health-the digestive functions being in no way impaired-eight months after its performance.

It is, I think, therefore well worthy of further trial ; but in order that it may be successful, it should only be performed in the early stage of the disease, when the pylorus alone is involved, and where the general condition of the patient is such, that he will be able to bear the severe shock which is necessarily attendant upon so serious an operation.

\section{THE DIAGNOSIS AND TREATMENT OF INTESTINAL OBSTRUCTION.}

\section{By H. T. BENHAM, M.D., Ipswich.}

CASES of intestinal obstruction are not uncommon; we ought, therefore, to study them carefully : for a prompt and accurate diagnosis of the actual state of matters is of immense importance. Time, instead of clearing up, obscures the diagnosis; superadding symptoms of general peritonitis, which hide the local signs. In acute cases, inflammation of the bowel tends rapidly towards gangrene, rendering operative help more and more useless, if not given at the earliest opportunity. Accurate diagnosis, at the first examination, should therefore be our aim; the right treatment then follows almost as a matter of course. Delay is often more dangerous than the boldest operation.

The diagnosis and treatment of external hernia is tolerably plain and settled. What is needed is, that, in cases where the obstruction is within the abdomen, our diagnosis should become equally certain, and the treatment equally prompt and decided. I would venture to submit that, in forming our opinion, these two great classes of intestinal obstruction (the external and the internal) should be considered together -not relegated, the one to the surgeon, and the other to the physician. Is it not illogical to postpone all thought of operative interference in the one case until it is too late, and the patient is moribund; whilst, in cases of external hernia, with the same general symptoms, the rule would be to operate at once?

The pathognomonic symptoms of intestinal obstruction are absolute constipation and repeated vomiting. If meningitis, peritonitis, renal and biliary colic, can be excluded, these symptoms point to a condition which should forbid all purgatives and irritating measures, and lead to a careful and searching examination. If obstruction be complete, distension of the bowel above soon comes on, with local pain, followed by increasing tenderness from local inflammation; more urgent vomiting; pyrexia; and, ultimately, unless relief be afforded, collapse and death. There is often marked anxiety of countenance, out of proportion to the pain.

In considering these cases, it is well, following Dr. Clifford Allbutt, to divide them, according to their previous history and mode of onset, into three classes.

J. Chronic.-Onset gradual, during weeks or months, without any very urgent symptoms.'

2. Late Acute. - Where, after a chronic course, a more or less acute attack of obstruction supervenes.

3. Early Acute. - Where symptoms of complete obstruction develop in a few hours, in a patient previously free from bowel-trouble.

The history should always be carefully noted, if possible, and the order in which the symptoms arose. The more urgent the symptoms, the more prompt must be our treatment ; whilst mildness of constitutional reaction, in obscure cases, may justify us in pursuing an expectant and soothing treatment-whereby, perhaps, the inflammation and swelling of the imprisoned bowel may be subdued, and the obstruction relieve itself without operative interference. Enteritis and peritonitis are the complications to be dreaded; should they be increasing, an operation is urgently demanded to save the patient's life; and this is the more likely to succeed, the earlier it is undertaken. In forming our diagnosis, we should first mentally exclude the more chronic causes of obstruction, one by one, till we arrive at the condition present.

Commencing, then, with the chronic cases: if there be no abdominal tenderness or pyrexia, the cause may be impaction of fæces; stricture, fibrous or cancerous; polypus; tumour or abscess compressing the bowel. If there be abdominal distension, with some pain and tenderness, this may arise from injury to the bowel (of which the history may tell), or it may indicate more or less enteritis and local peritonitis. Should a chronic course have been interrupted by an acute exacerbation, we have an instance of the late acute class, where the conditions are more urgent. Yet here, if we be sure that the original condition was chronic, and especially if we have evidence of an old fixed cause of obstruction in the writhings of distended hypertrophied bowel above it, we may be able, by giving the parts functional rest by almost total abstinence from food, and by soothing by heat, opium, and belladonna, to subdue the inflammation and restore matters to a chronic state, which can be dealt with at leisure. Hence the importance of obtaining an accurate history.

With the late acute cases may be considered a very important group - that of intussusception-which sometimes belongs to the late acute, and sometimes, as in the typical cases, to the early acute class; though it may almost be considered as a class by itself. When it is acute, with frequent tenesmus and passage of blood-stained mucus, with an elongated, painful, movable tumour, the diagnosis is clear. Chronic forms are not so obvious; and there is one condition-perityphlitis, or inflammation around the cæcum and vermiform appendix, which closely simulates intussusception. It may be distinguished generally by a history of pain and swelling antecedent to the vomiting and constipation; and, if there be a doughy or brawny infiltration of the integuments, the case and the treatment become obvious.

All these cases hitherto mentioned should be considered first. In addition to the soothing treatment, a very valuable plan is for the surgeon himself to inject a cupful or more of olive-oil, and then as many pints of warm water or gruel as he can, proceeding slowly and carefully, lest inflamed bowel be ruptured. With due care, this need not happen; and much valuable information is gained as to the site of the obstruction and its cause. By this means, fæcal masses may be broken up, and an intussusception may be reduced. If the lower end of it can be felt getting lower and lower, there is every reason to expect success in reduction; but, if there be much tenderness about the tumour, and it do not alter in shape, much care must be exercised. When once the layers are glued together, the only hope of cure lies in the slough. ing off of the contained portion, which may occur in four cases out of ten. It there be stricture, injections will do no good, but the contrary. Then it becomes necessary, when it is no longer possible to obtain ease by regulating the diet, and by saline laxatives, or, in some cases, by dilatation, to consider the question of colotomy. This operation is generally neither difficult nor dangerous, and seems far preferable to the habitual use of morphia for months. Should there be tenderness and distension of the cæcum, colotomy should be performed on the right side, even if the stricture be in the sigmoid flexure; but the operation should not be deferred until this is necessary.

Of course, in considering a late acute case, the possibility of there being an external hernia must not be overlooked. Pain shooting down the inner side of the thigh may lead to the discovery of an obturator hernia.

But, if we can certainly exclude all these causes of obstruction, and the case evidently belong to the early acute group, we are brought face to face with a very important because most urgent case. It is no longer allowable to suspend our judgment and wait, hoping that inflammation will subside and all go well. This may happen under judicious treatment, but not in the acuter cases.

The symptoms point to acute strangulation of bowel, either within the abdomen or external to it; and we should judge of the condition of the bowel just as we do in cases of external hernia. Of course, all the usual and unusual sites must be explored; and, if found, the hernia dealt with according the rules of surgery. But, if none can be found, I contend that these rules are still applicable to the case. If the constitutional symptoms indicate no great amount of damage to the bowel, we may soothe, and wait a few hours, persevering in this line of treatment if there be improvement; but, if the condition of the patient become more and more urgent, there is no time to be lost. If the bowel be running on towards gangrene, it may rupture, and fatal peritonitis rapidly occur. Even the release of the imprisoned bowel may come too late, if its tissues be allowed to mortify first. Therefore it is of the highest importance to realise, as early as possible, the true state of affairs; and, if we feel sure that there is an acutely-strangulated loop of bowel somewhere, it is our plain duty to set it free. This can be done by laparotomy, or abdominal section. The abdomen is opened in the linea alba, the hand introduced, and the bowel released, with as little disturbance as possible. But, if it be in a doubtful state, it should be secured close to the edge of the wound, the abdomen thoroughly cleansed, and drainage provided for. In an early operation, this can be dispensed with advantageously. If there be a history of dragging pains at one spot in the abdomen, following an attack of peritonitis, we shall probably find and divide at that spot a constricting band of fibrous tissue. These are the most hopeful cases. But for impaction 
of foreign insoluble bodies or gall-stones, for twists and internal hernix, laparotomy, performed early, offers the best and almost the only chance, if the strangulation be acute; and I believe the time will soon come when this operation will take its place in surgery side by side with the parallel operation of kelotomy for external strangulated hernia. It is a question of diagnosis. Let us, then, strive to make our diagnosis of these grave cases more thorough and more certain.

\section{CASE OF INTESTINAL OBSTRUCTION, AND ABDOMINAL SECTION.}

By CHARLES FIRTH, M.B.,

Assistant-Surgeon to the Norfolk and Norwich Eye Infirmary, ctc.

R. C., labourer, age $i 49$, was admitted into hospitai on July $3 \mathrm{rd}$, 1877 , with left scrotal hernia, and the following history. He had had a rupture for five years, and had always worn a truss. On June 29 th, at 8 A.M., he was carting bricks, when he felt a sudden pain in the left groin, and the hernia became larger. (The truss for the last month had failed to keep up the hernia.) He was sick once on June $29^{\text {th }}$, but the vomiting became urgent on July Ist, and had continued since. On admission, he had a large left inguinal hernia, which was easily reduced, but the vomiting continued. Pulse weak, and small, II 2 ; tongue white, but moist. The abdomen was tympanitic, tender, and tense. He was very thirsty. The vomited matter was offensive, brownishyellow, not frecal. The bowels were open three times"on June 29thnot since. He had had hiccough since the 29 th.

At 10.45 P.M., a consultation was held; and, at II, under ether, the abdomen was explored, but no strangulation was detected. Stercoraceous vomiting occurred during the operation.

On July 4th, 3 A. M., frecal vomiting continued. There was retention of urine. He had stricture. A No. 3 flexible catheter was passed and kept in.

July 4th, 10.30 A.M. He had a great deal of pain in the abdomen in the night, which was better this morning. The abdomen was very tense. Pulse I28, weak and thready; temperature $97^{\circ}$ to $98^{\circ}$; hiccough continued. Three sutures had given way, and were replaced by others. In the evening, sickness had been much less frequent since I P.M., and the vomited matter was not stercoraceous. Temperature $98.8^{\circ}$; pulse ro8.

July 5 th. The bowels were opened eight times since 2 P.M. yesterday. He was sick slightly this morning, slept fairly in the night, and had had no pain. Temperature $97.8^{\circ}$; pulse I04, of fair volume. The tongue was moister; he had no hiccough. Carbolic water dressing was applied to the wound.

July 6th. He was sick once in the afternoon. Pulse 108 ; temperature $98.2^{\circ}$. At 5 A.M., sickness returned; he had great pain and distension of the abdomen. At I I A.M., he was vomiting a dark fluid, and was in great pain. The pulse was almost imperceptible, and the extremities cold. At 2 P.M., he died.

Post mortem Examination.-The abdomen was enormously distended, and tympanitic. On opening the abdomen, the coils of small intestine were found firmly adherent to the wound. There was no general peritonitis, but only congestion and loss of polish of the peritoneal surface. The cæcum was greatly distended with fluid and sanious frecal matters. One part, as large as half-a-crown, was greatly thinned, sloughy on the inside, and perforated in two places by two pin-hole openings. The crecum was found lying under the diaphragm, close to the spleen, the large intestine attached to it having been twice twisted round the lengthened mesentery of the small intestine, causing a double obstruction. The other organs in the body were tolerably healthy.

\section{REMARKS UPON' THE ADVANTAGE OF THE EMPLOYMENT OF WIRE LIGATURES FOR THE APPROXIMATION OF DIVIDED BONES.}

BY T. SYMPSON, F.R.C.S., Surgeon to the Lincoln County Hospital.

ALL surgeons who operate frequently are aware of the extreme im. portance of placing and preserving the divided surfaces of bones in very accurate contact in such operations as those of excision of the knee, supracondyloid amputation of the lower extremity, Pirogoff's amputation at the ankle-joint, and the like. It is a well known and universally realised fact, that neglect of this precaution is apt to lead to disastrous results, and to the failure of operations otherwise well planned and satisfactorily carried out. Such neglect is often followed by ulceration or necrosis of the bones, and the formation of immense quantities of pus. The limb, riddled by sinuses, becomes an incumbrance to its owner, and, in order to save the life of the patient, has to be got rid of by amputation.

Although, twenty-one years ago, Professor Cocper of San Francisco advocated the treatment of fractured patella by means of silver wire, yet, as an addition to other means for obtaining accurate approximation of the sawn surfaces of bones, the use of wire sutures seems scarcely to have met with that recognition among practical surgeons which its merits appear to claim. I therefore, lventure to call attention to two cases in which I employed it, and in which it clearly proved of very great service in securing the union of bones in a good position.

The first case was that of a healthy man, thirty years of age, whose foot was run over by a ballast-train on the Great Northern Railway, in consequence of which he was admitted into the Lincoln County Hospital on May 24th, I88I. On examination, the anterior and middle portions of the foot were found to be completely smashed, but the heel was intact. I therefore determined to amputate after Pirogoff's method, retaining the opposed portions of tibia and os calcis in position by the introduction of iron wires. The operation-wound was completely healed in ten days, but it was thought desirable to retain the wires for six weeks, at the expiration of which time the bones were found to be well united. The man staid seven weeks in the hospital. He can now walk well with the aid of a properly adapted shoe.

The other case to which I wish to draw your attention was that of a boy seven years of age, who was admitted into the Lincoln County IIospital on June 2oth, I88r, for disease of the knee-joint of three years' duration, following an injury from his having slipped upon the pavement. The knee was much swollen, very painful and tender, and yielded a profuse purulent discharge through a long sinus on the outer aspect of the thigh. The boy was extremely feeble and emaciated, but had no visceral disease. On July 26th, I excised the joint, the incisions being a transverse one below the patella joined by a longitudinal one along the course of the sinus. On exposure of the surfaces of the bones, they were seen to be almost entirely denuded of cartilage, and in the head of the tibia were two masses of caseous material, each of the size of a walnut. These were removed by the gouge. The sawn surfaces of the femur and tibia were brought firmly together by two wire sutures, one on the outer, the other on the inner aspect, and iron splints applied, the posterior one being hollowed out on each side opposite the knee, and the anterior one arched in the corresponding position. These were retained in situ by a paraffin bandage, and the limb was swung from a cradle. The wound of the operation was completely healed in about two months, when, as the bones were found united, the wire sutures were removed. Unfortunately, a slough, due to the pressure of the splint, formed over the crest of the tibia; and partly in consequence of the time required for the healing of the sore thus occasioned, and partly from the wretched state of the home of the boy, he did not leave the hospital until October 24th, when he could bear weight upon the limb, which was shortened about an inch and a half.

It will be noticed that, at first sight, this appeared a most unfavourable case for operation, from the ill nourished condition of the child, the great amount of disease of the joint, the presence of a long sinus, and especially from caseous masses being imbedded in the head of the tibia. The termination of the case, however, is singularly satisfactory, as the boy now possesses an excellent limb, but slightly shortened, upon which he can walk well; a result which, I feel sure, is mainly due to the measures taken to preserve the complete immobility of the bones.

Both these operations were performed under strict antiseptic precautions, and in neither of them was any irritation caused by the wire. With regard to the method of introduction of the wires, it is desirable that the apertures made by the drill should be at least a quarter of ar. inch from the sawn surfaces, and that these surfaces should be very accurately approximated by twisting together the ends of the wires. It is preferable not to twist these ends more than twice, as otherwise considerable difficulty will be found in effecting their removal. Iron wire, such as that used for the stilets of elastic gum catheters, in size about No. 22 of the gauge, will usually be found the best.

THE Liberal de Seine-et-Oise, announces that a family consisting of six persons has been poisoned at Mureaux in the department of the Seine-et-Oise through eating poisonous fungi. Medical aid was summoned, but all six died in great suffering. The victims are a mo ther, her three daughters (aged 25, 19, and I 5 years respectively), her son (aged I4), and her son-in-law. Special care should be exercised in the selection of fungi for edible purpose in a wet season like the present when the growth is likely to be profuse and rank. 